\title{
Spectroelectrochemical Studies of Interactions between Vitamin A and Nanocolloidal Silver
}

\author{
Bogdan Tutunaru*, Adriana Samide, Cristian Neamțu, Cristian Tigae \\ University of Craiova, Faculty of Sciences, Department of Chemistry, Calea Bucureşti 107i, 200478, \\ Craiova, Dolj, Romania \\ *E-mail: tutunaruchim@yahoo.com
}

doi: $10.20964 / 2018.06 .64$

Received: 28 January 2018 / Accepted: 26 March 2018 / Published: 10 May 2018

\begin{abstract}
The electrochemical stability of retinyl palmitate (RP) known as Vitamin A in mixed water/ethyl alcohol solutions containing $\mathrm{NaCl}$ or $\mathrm{NaNO}_{3}$, in the absence and presence of silver nanoparticles (nAg) was investigated by cyclic voltammetry $(\mathrm{CV})$ recorded on platinum electrode. The chemical interaction between retinyl palmitate and silver nanoparticles was also studied using UV-Vis spectrophotometry applied on the above mentioned media. The experimental results obtained from UV-Vis spectrophotometry showed that in the presence of $\mathrm{NO}_{3}{ }^{-}$ions, weak RP-nAg interaction takes place, while in the presence of chloride ions a significant change in environment composition has been highlighted due to the occurrence of instantaneous RP-nAg interaction. The cyclic voltammetry displayed different shapes of cyclic voltammograms recorded on platinum electrode in water/alcohol solutions containing $\mathrm{RP}$ and $\mathrm{RP} / \mathrm{nAg}$ in the presence of $\mathrm{NO}_{3}{ }^{-}$ions compared to those recorded in $\mathrm{Cl}^{-}$ presence due to the specific interaction RP-nAg depending on the anion type. Thus, $\mathrm{NO}_{3}{ }^{-}$addition leads to mainly electrochemical interaction compared to $\mathrm{Cl}^{-}$presence that favors chemical $\mathrm{RP}-\mathrm{nAg}$ interaction. Based on the cyclic voltammetry results obtained in the presence of $\mathrm{NO}_{3}{ }^{-}$ions, the electrochemical decomposition mechanism of Vitamin A was proposed.
\end{abstract}

Keywords: Retinyl palmitate; Silver nanoparticles; Cyclic voltammetry; UV-Vis spectroscopy.

\section{$\underline{\text { FULL TEXT }}$}

(C) 2018 The Authors. Published by ESG (www.electrochemsci.org). This article is an open access article distributed under the terms and conditions of the Creative Commons Attribution license (http://creativecommons.org/licenses/by/4.0/). 